Article

\title{
The Tribological Performance of CrMoN/MoS 2 Solid Lubrication Coating on a Piston Ring
}

\author{
Yuelan Di *, Zhihai Cai and Ping Zhang \\ Department of Equipment Remanufacturing Engineering, Academy of Armored Forces Engineering, \\ Beijing 100072, China; caizhihai2052@163.com (Z.C.); zhangp5801@sina.com (P.Z.) \\ * Correspondence: dylxinjic031@163.com; Tel.: +86-10-6671-9249 \\ Academic Editor: Zhengyi Jiang \\ Received: 24 February 2017; Accepted: 12 April 2017; Published: 23 May 2017
}

\begin{abstract}
In order to improve the tribological properties of an engine piston ring and enhance its service life, magnetron sputtering technology and low temperature ion sulphurizing treatment technology were used to prepare $\mathrm{CrMoN} / \mathrm{MoS}_{2}$ solid lubricant coating on the surface of an engine piston ring. The morphologies and compositions of the surface and cross-section of the sulfuration layer were analyzed by field emission scanning electron microscopy (FESEM), and wear property under high load, high speed and high temperature conditions were tested by a SRV ${ }^{\circledR} 4$ friction and wear testing machine. The results show that the $\mathrm{CrMoN} / \mathrm{MoS}_{2}$ composite coatings appear as a dense grain structure, and the coating is an ideal solid lubrication layer that possesses an excellent high temperature wear resistance, reducing the engine operating temperature abrasion effectively and prolonging the service life of the engine.
\end{abstract}

Keywords: $\mathrm{CrMoN} / \mathrm{MoS}_{2}$; magnetron sputtering; low temperature ion sulfurizing; solid lubrication; wear mechanism

\section{Introduction}

A piston ring and cylinder is the most important friction pair, which is often used in harsh environments under conditions of high speed, high temperature, and high load. The loss of wear caused by the friction pair is a key problem that reduces engine life [1-3]. According to the survey data of a tank engine major repair shop [1], after $500 \mathrm{~h}$ of use, the wear on all piston rings is very serious and the parts must be scrapped, which not only reduces the service life of the engine, but also causes a lot of waste. How to reduce the wear of the piston ring and cylinder has become a main research aim of many scholars.

At present, the conventional plating $\mathrm{Cr}$ process has been adopted to strengthen the piston ring of heavy-duty vehicle engines and it is popularly used in the industry [4,5]. Although this method has shown some improvement in wear resistance, the pollution caused by the traditional electroplating $\mathrm{Cr}$ process and the call for continuous improvement of piston ring performance indicate that there is still a need for better solutions in surface treatment technology of piston rings. The results show that the friction and wear properties of a piston ring treated by ion plating are improved significantly compared with that of $\mathrm{Cr}$ plating, and this method also can reduce the environmental pollution and human resources wastes [6].

CrMoN $[7,8]$ composite coatings, which are deposited by magnetron sputtering technique, have been extensively studied for many of the promising properties, such as extensive hardness and a low friction coefficient. Although the existence of the self-lubricant $\mathrm{MoO}_{3}$ during the friction and wear process can reduce the friction coefficient, it is limited and can not meet the needs of rigorous working parts (such as piston rings) with its limited lubricating effects [7]. Low temperature ion sulfurization technique can be used to generate a loose and porous sulfur layer with low shear strength and good 
lubricating properties $[9,10]$. In this paper, $\mathrm{CrMoN} / \mathrm{MoS}_{2}$ solid lubricant coating was prepared on the surface of an engine piston ring, compared with the traditional $\mathrm{Cr}$ coating, and the high temperature wear resistance of these two coatings was investigated.

\section{Experimental Method}

\subsection{Coating Preparation}

$\mathrm{CrMoN} / \mathrm{MoS}_{2}$ coatings were prepared in two steps. In the first step, Cr-Mo-N coating was deposited using a TEER UDP-650 closed-field unbalanced magnetron sputtering coater (Huijinteer coating technology Co., Ltd. Zhejiang, China). The substrates were $65 \mathrm{Mn}$ steel wafers $(40 \mathrm{~mm} \times 30 \mathrm{~mm} \times 1 \mathrm{~mm})$ and silicon (100) wafers. The layout is shown in Figure 1 . The substrate holder rotated around a vertical center, which could provide a uniform exposure for growing the film. A mixture of argon and nitrogen were injected when sputtering. Argon flow was set at $35 \mathrm{sccm}$, while nitrogen flow was controlled by an Optical Emission Monitor (Huijinteer coating technology Co., Ltd. Zhejiang, China). The deposition chamber was first evacuated to $2.0 \times 10^{-3}$ Pa with a mechanical pump, and then was pumped to a high vacuum of $2.0 \times 10^{-3} \mathrm{~Pa}$ with a diffusion pump. At the same time, the temperature of the vacuum chamber was heated up to $100^{\circ} \mathrm{C}$. The $\mathrm{Cr}$ target current was fixed at 3A; the Mo target current was 5A. After depositing, the vacuum was kept insulated for 20-40 min. Resulting from this preparation, the thickness of $\mathrm{CrMoN}$ composite coatings was about $5.0 \mu \mathrm{m}$.

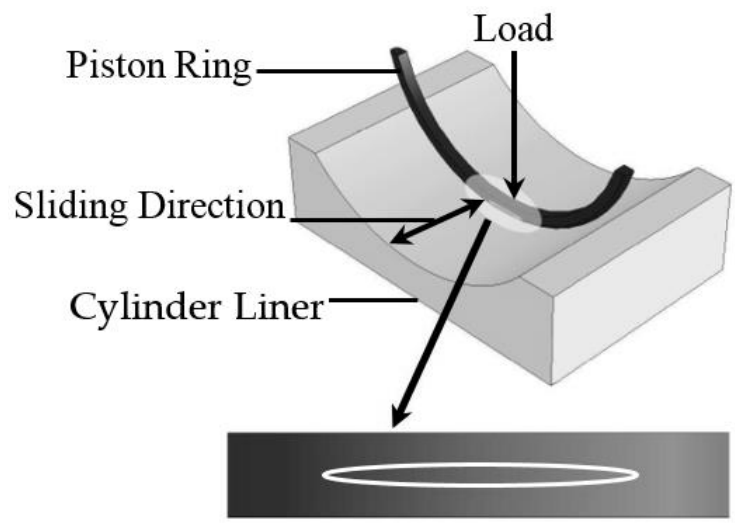

Figure 1. The contact mode and movement of piston ring and cylinder liner.

In the second step, Cr-Mo-N coatings were sulfurated in the equipment of model DW- 1 for $2.5 \mathrm{~h}$. The reacting gas was solid sulfur vapor. The workpiece was connected to the cathode, while the furnace acted as the anode. When the vacuum was up to a certain value, the chamber was filled with ammonia gas, and a high voltage of $800 \mathrm{~V}$ was applied between the anode and the cathode. Ammonia ions were accelerated to bombard the cathode (workpieces), elevating their temperature to convert the sulfur into gas. This bombardment continued until the temperature reached the scheduled value of $230^{\circ} \mathrm{C}$.

The specifications of the commonly used electroplating $\mathrm{Cr}$ process are as follows: $\mathrm{CrO}_{3}$ 230-270 g/L, Cr ${ }^{3+}: 2-5, \mathrm{CrO}_{3}: \mathrm{H}_{2} \mathrm{SO}_{4}=100: 1( \pm 0.1), t=55 \pm 2{ }^{\circ} \mathrm{C}, D_{\mathrm{k}}=50-55 \mathrm{~A} / \mathrm{dm}^{2}$. The thickness of the Cr plating was about was about $0.1 \mathrm{~mm}$.

\subsection{Performance Test Method}

The microstructure and cross-sectional morphology of the coatings were characterized by a field emission scanning electron microscope (FESEM) and an X-ray diffractometer. The chemical valence states of the coatings were carried out by an ESCALAB 250iXL (VG Scientific, Thermo Fisher Scientific, Waltha, MA, USA) type spectrometer. Scanning Augur Microprobe (PHI 700, ULVAC-PHI, Chigasaki, Japan) was utilized to analyze the distribution of elements along the layer depth. 
The hardness of the multilayer films was measured by using multi-function nanotest 600 hardness-testing devices. In order to simulate the actual motion of the piston ring and cylinder in the engine, the tribological properties of the composite coatings were performed on an SRV ${ }^{\circledR}$ high temperature friction and wear testing machine (Figure 1). The upper sample is taken from a part of the actual spherical trapezoid ring, which was coated with $\mathrm{Cr}$ plating and $\mathrm{CrMoN} / \mathrm{MoS}_{2}$ solid lubricant coating. The lower sample is made from the actual cylinder liner, and the material is $42 \mathrm{MnCr} 52$ steel. In the test process, the lower sample is fixed, while the upper sample is in motion. The test condition is under poor lubrication condition [11], as shown in Table 1.

Table 1. Friction test condition.

\begin{tabular}{ccccc}
\hline Load/N & Frequency/Hz & Temperature $/{ }^{\circ} \mathbf{C}$ & Time/s & Stroke/mm \\
\hline 50 & & & & \\
170 & 20 & 100 & 7200 & 4 \\
290 & & & & \\
400 & & & \\
\hline
\end{tabular}

\section{Results and Discussion}

\subsection{Component and Phase Structure}

The component analysis results of CrMoN composite coating is shown in Table 2. The atomic percentage of $\mathrm{N}$ content in the coating and the sum of the atomic percentage of $\mathrm{Cr}$ and Mo ratio is about 1 to 1 , which conforms to the stoichiometric ratio. The chemical formula can be expressed as $\mathrm{Cr}_{1-x} \mathrm{Mo}_{x} \mathrm{~N}$, where $x$ represents the proportion of Mo in all metal content; $x=\mathrm{Mo} /(\mathrm{Cr}+\mathrm{Mo})=0.65$. After sulfurizing, the $\mathrm{Cr}$ and Mo content in the $\mathrm{CrMoN}$ composite coating decreases slightly. This is because, in the first half of the sulfurizing treatment process, the CrMoN composite coating, which was fixed in the cathode, was bombarded by ammonia ions. Thus, parts of Mo and Cr ions sputtered out from the CrMoN composite coating surface, and $\mathrm{S}$ atoms subsequently permeated the coating along the defects and the grain boundary.

Table 2. The component analysis result of coatings.

\begin{tabular}{cccccc}
\hline \multirow{2}{*}{ Coatings } & \multicolumn{2}{c}{ As Deposited } & \multicolumn{3}{c}{ Sulfurized } \\
& $\mathrm{Cr}$ & Mo & $\mathrm{Cr}$ & Mo & S \\
\hline $\mathrm{Cr}_{0.35} \mathrm{Mo}_{0.65} \mathrm{~N}$ & $17.07 \%$ & $33.27 \%$ & $14.93 \%$ & $28.17 \%$ & $6.9 \%$ \\
\hline
\end{tabular}

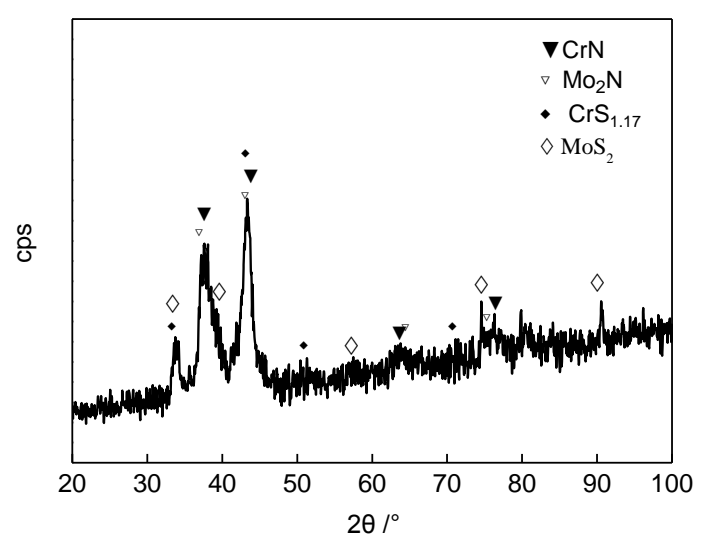

Figure 2. XRD patterns of $\mathrm{CrMoN} / \mathrm{MoS}_{2}$ composite coating.

Figure 2 shows the XRD pattern of the $\mathrm{CrMoN} / \mathrm{MoS}_{2}$ composite coatings. As seen in Figure 2a, the broadened peaks are the mixed phases of both the $\mathrm{CrN}$ and $\gamma-\mathrm{Mo}_{2} \mathrm{~N}$ phases. However, the differences 
in diffraction angle were too small to identify two separate phases, which was caused by the existence of both the $\mathrm{CrN}$ and $\mathrm{Mo}_{2} \mathrm{~N}$ phases on only one nanocrystal. It can be seen that a strong peak centered at approximately $2 \theta=33.8^{\circ}$, which corresponds to the (100) plane of molybdenum sulfide and chromium sulfide. Two broadened peaks are also observed, one peak centered at $2 \theta=57^{\circ}$ and the other peak centered at $2 \theta=76^{\circ}$, indicating that a nanocrystal or an amorphous solid existed in the $\mathrm{CrMoN} / \mathrm{MoS}_{2}$ composite coating.

\subsection{XPS Analysis}

The X-ray photoelectron Spectroscopy (XPS) analysis results of the chemical valence states of $\mathrm{CrMoN} / \mathrm{MoS}_{2}$ coatings are shown in Figure 3. The peaks of $\mathrm{Cr} 2 \mathrm{p} 3 / 2$ were the compound of $\mathrm{Cr}-\mathrm{S}$, $\mathrm{Cr}-\mathrm{N}$ and $\mathrm{Cr}-\mathrm{O}$, where the bonding energy was $574.4,575.3$ and $576.8 \mathrm{eV}$, respectively. The appearance of $\mathrm{Cr}-\mathrm{O}$ may be attributed to surface oxide pollution. The peak of Mo emerged in the same place as the superposed peaks of $\mathrm{Mo}(228 \mathrm{eV})$ and Mo-S $(229 \mathrm{eV})$. The peak of Mo-N also appeared where the bonding energy was $231.5 \mathrm{eV}$. The bonding energy of $\mathrm{S} 2 \mathrm{p}$ was 161.3 and $162.5 \mathrm{eV}$, which corresponded to $\mathrm{Cr}-\mathrm{S}$ and $\mathrm{Mo}-\mathrm{S}$. In addition, $\mathrm{S}-\mathrm{N}$ was also can be observed but not significantly, so it was not able to be analyzed in the XRD results.
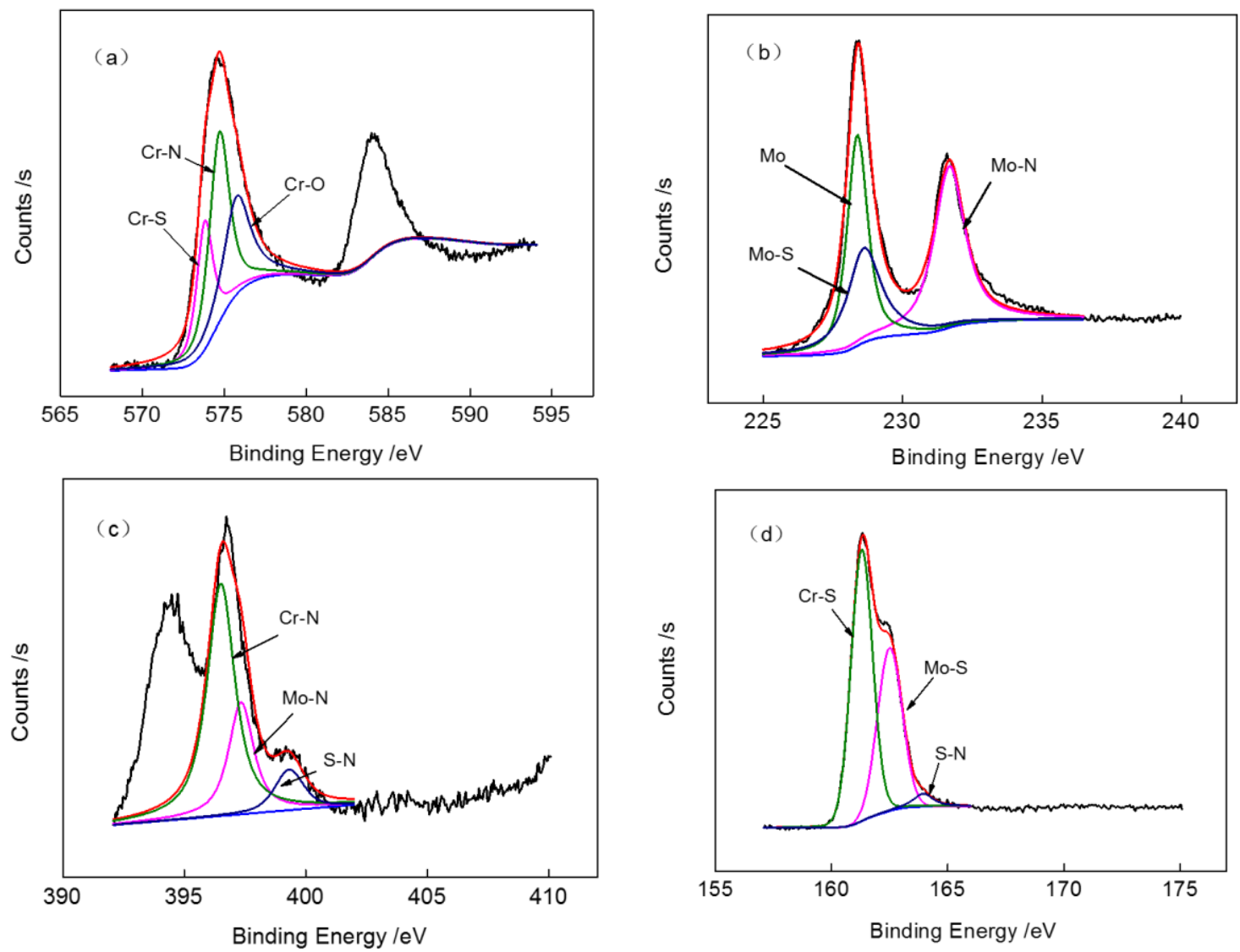

Figure 3. X-ray photoelectron Spectroscopy (XPS) analysis of CrMoN/MoS 2 coatings (a) Cr2p; (b) Mo3d; (c) N1s; (d) S2p.

\subsection{Surface Morphologies}

The scanning electron microscopy (SEM) micrographs of the $\mathrm{Cr}$ and $\mathrm{CrMoN} / \mathrm{MoS}_{2}$ coatings are shown in Figure 4. It can be seen that the morphology of the $\mathrm{CrMoN} / \mathrm{MoS}_{2}$ coating is entirely different from the Cr plating. The surface of the $\mathrm{Cr}$ plating is lamellar particles, while the $\mathrm{CrMoN} / \mathrm{MoS}_{2}$ composite coating reveals a dense and smooth surface structure. The grains of the $\mathrm{Cr}$ plating are larger than those of the $\mathrm{CrMoN} / \mathrm{MoS}_{2}$ composite coating. 
The cross-section morphology of the $\mathrm{Cr}$ and $\mathrm{CrMoN} / \mathrm{MoS}_{2}$ coatings are shown in Figure 5. It can be seen that the interface of the two coatings are all columnar crystal structures, the only difference being that the grain of the $\mathrm{Cr}$ plating is larger. The $\mathrm{CrMoN} / \mathrm{MoS}_{2}$ coating is built up with two layers. On the bottom is a $\mathrm{Cr} / \mathrm{CrN}$ transition layer, and on the top is a $\mathrm{CrMoN}$ composite layer. The sulfide particles heap together, layer by layer, on the top of the $\mathrm{CrMoN} / \mathrm{MoS}_{2}$ composite coating, and the thickness of the surface sulfide layer is about $1 \mu \mathrm{m}$. Sulfurizing processing is a process of combination, dissociation and diffusion, in which the sulfide layer is formed by the absorption and deposition of sulfide particles. Under the bombardment of sulfur ions, parts of the sulfide layers are decomposed to sulfur ions or sulfur atoms, while the rest diffuses into the inner layer at high temperature. However, the diffusion speed of sulfur is limited and thus it only diffuses along the grain boundary and dislocates by short circuit diffusion. Therefore, the sulfide layer is thinner.
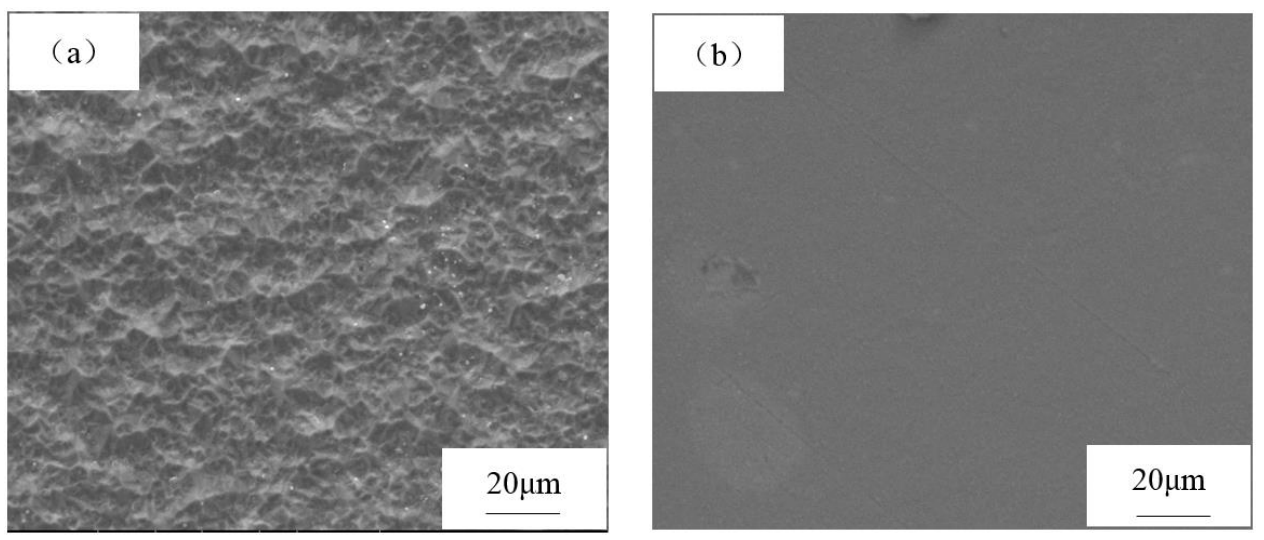

Figure 4. Surface morphologies of $\mathrm{Cr}$ plating (a) and the $\mathrm{CrMoN} / \mathrm{MoS}_{2}$ composite coating (b).
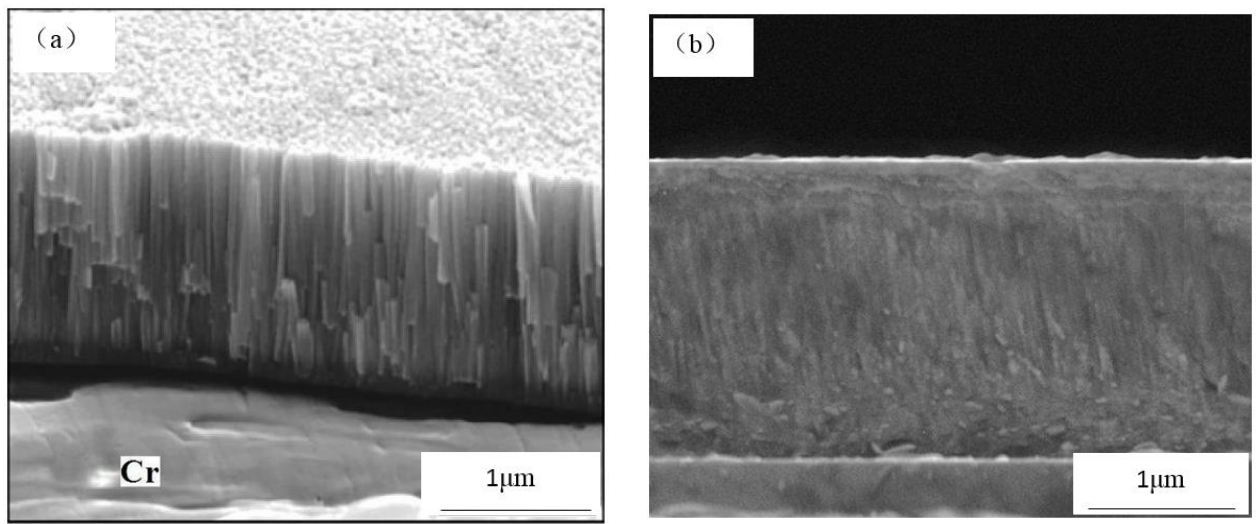

Figure 5. Cross-section morphology of $\mathrm{Cr}$ plating (a) and the $\mathrm{CrMoN} / \mathrm{MoS}_{2}$ composite coating (b).

\subsection{Nanoindentation}

The nano-hardness test results of $\mathrm{Cr}$ plating and the $\mathrm{CrMoN} / \mathrm{MoS}_{2}$ composite coating are listed in Table 3; all the results are the average values between 300 and $400 \mathrm{~nm}$. It can be seen that the average nano-hardness and Young's modulus of the $\mathrm{CrMoN} / \mathrm{MoS}_{2}$ composite coating were 29.2 and 347.1, respectively, which are much higher than those of $\mathrm{Cr}$ plating (5.4 and 194.7, respectively). Therefore, the resistance of plastic deformation was enhanced. The reason for this can be analyzed as follows: (1) Fine grained strengthening. The refinement of the grains of the $\mathrm{CrMoN} / \mathrm{MoS}_{2}$ composite coating created more dislocations at the grain boundaries, thus the size of the grains of the surface layer is less than $30 \mathrm{~nm}$; (2) Symplastic growth. During the sulfurizing process, $\mathrm{S}$ atoms that come from the intracell can replace $\mathrm{N}$ atoms to form $\mathrm{MoS}_{2}$, which strengthens the inter-formational bonding force. Although the crystallization of $\mathrm{MoS}_{2}$ usually has a lower hardness, amorphous $\mathrm{MoS}_{2}$ has 
relatively high hardness, such as the $\mathrm{MoS}_{2}-\mathrm{Ti}$ composite coatings (trade-marked by Teer Coatings Ltd. as MoST ${ }^{\mathrm{TM}}$, Worcestershire, UK) that have shown excellent hardness and adhesion of the coatings, showing great improvements of wear-resistance properties in comparison with conventional hard coatings [12]. So, the relative high hardness of the $\mathrm{CrMoN} / \mathrm{MoS}_{2}$ composite coatings may be due to the formation of the amorphous $\mathrm{MoS}_{2}$ in the coatings. $\mathrm{CrN}$ and $\mathrm{MoN}$ hard phases can stand the $\mathrm{MoS}_{2}$ soft phase, and the interphase interaction of hard and soft phases can improve the mechanical properties of the $\mathrm{CrMoN} / \mathrm{MoS}_{2}$ composite coatings as well as enhance their antifriction and abrasive resistance.

Table 3. The nano-hardness test results.

\begin{tabular}{ccccc}
\hline Coatings & H/GPa & E/GPa & $H^{3} / E^{2} / G p a$ & $D_{\text {max }} / \mathbf{N M}$ \\
\hline $\mathrm{Cr}$ & 5.4 & 194.7 & 0.004 & 1063.453 \\
$\mathrm{CrMoN} / \mathrm{MoS}_{2}$ & 29.2 & 347.1 & 0.207 & 1027.832 \\
\hline
\end{tabular}

\subsection{Friction Behavior}

Figure 6 depicts the friction coefficient curve under different static loads of piston ring-cylinder friction pairs with either $\mathrm{Cr}$ plating or $\mathrm{CrMoN} / \mathrm{MoS}_{2}$ coating. It can be seen that these two kinds of friction coefficients with different coatings on piston ring-cylinder friction pairs both decreased as the load increased, and this result was not affected by error. When the load increased from $50 \mathrm{~N}$ to $170 \mathrm{~N}$, the friction coefficient decreased sharply, while when the load increased from 170 to $400 \mathrm{~N}$, the friction coefficient dropped more gently. In the friction process, when the load increases, friction surface asperities deformation occurs and the contact areas increase. Due to the two kinds of coatings, the piston ring shows a higher hardness and carrying capacity, and the ratio of the load increment is greater in proportion to the increment of shear force and contact area $[13,14]$. When the load changes from 50 to $400 \mathrm{~N}$, the friction coefficient of the $\mathrm{Cr}$ electroplated piston ring decreases about 26\%, while the piston ring with $\mathrm{CrMoN} / \mathrm{MoS}_{2}$ coating decreasing about $40 \%$. The friction coefficient of the $\mathrm{CrMoN} / \mathrm{MoS}_{2}$ coating is lower than that of the Cr plating and, especially at a high load of $400 \mathrm{~N}$, the anti-friction performance is obvious.

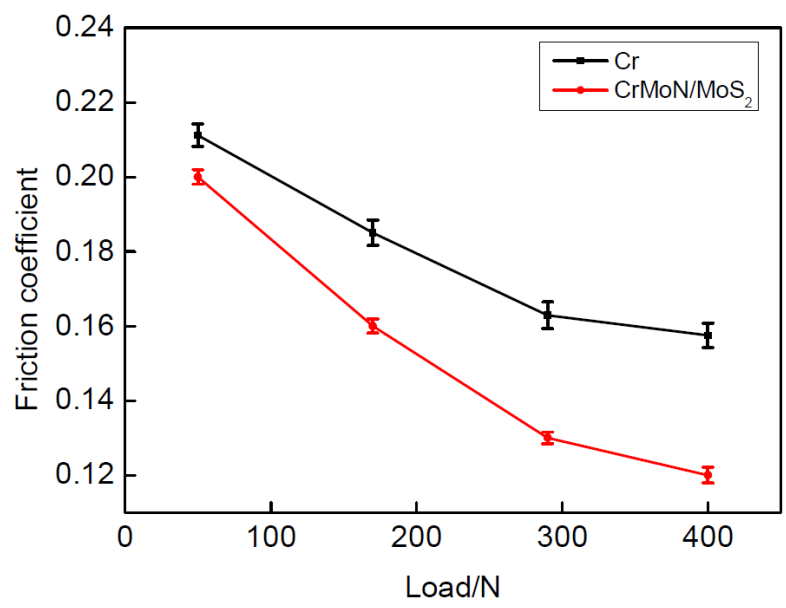

Figure 6. The friction coefficient of two kinds of coatings with load changing.

Figure 7 shows the wear weight loss of the piston ring-cylinder liner friction pairs with $\mathrm{Cr}$ electroplating and $\mathrm{CrMoN} / \mathrm{MoS}_{2}$ coating. As is shown in the figure, the total weight loss of the two kinds of coated friction pairs increases with the increase of the load. The wear loss of the CrMoN/MoS 2 coating on the piston ring-cylinder liner friction pair is significantly lower than that of the $\mathrm{Cr}$ friction pair. When the load is 50 and $170 \mathrm{~N}$, the total weight loss increases more slowly. The total weight loss increases more obviously when the load exceeds $170 \mathrm{~N}$. When the load is $400 \mathrm{~N}$, the total weight loss of 
the $\mathrm{Cr}$ friction pair increases about $50 \%$, while the $\mathrm{CrMoN} / \mathrm{MoS}_{2}$ coating friction pair increases about $39 \%$, showing a better wear resistance.

Figures 8 and 9 depict the wear scar morphology of $\mathrm{Cr}$ and $\mathrm{CrMoN} / \mathrm{MoS}_{2}$ coatings under different load conditions. From Figure 8, there is a slight furrow on the surface of the $\mathrm{Cr}$ plating of the piston ring due to the plough action of grinding, and some small and shallow scratches are on the cylinder liner surface. The wear mechanism of the $\mathrm{Cr}$ plated piston ring and cylinder liner is mainly abrasive wear (Figure 9a1,a2). The wear traces of abrasive wear on the piston ring and cylinder liner surface increase as the load increases (Figure $9 \mathrm{~b} 1, \mathrm{~b} 2, \mathrm{c} 1, \mathrm{c} 2$ ). The wear weight loss increases as the pressure in the contact surface increases. When the load increased to $400 \mathrm{~N}$, there is serious abrasive wear and adhesive wear, caused by friction heat in the friction process. The wear mechanism of the piston ring transferred to abrasive wear and adhesive wear, as well as the cylinder liner.

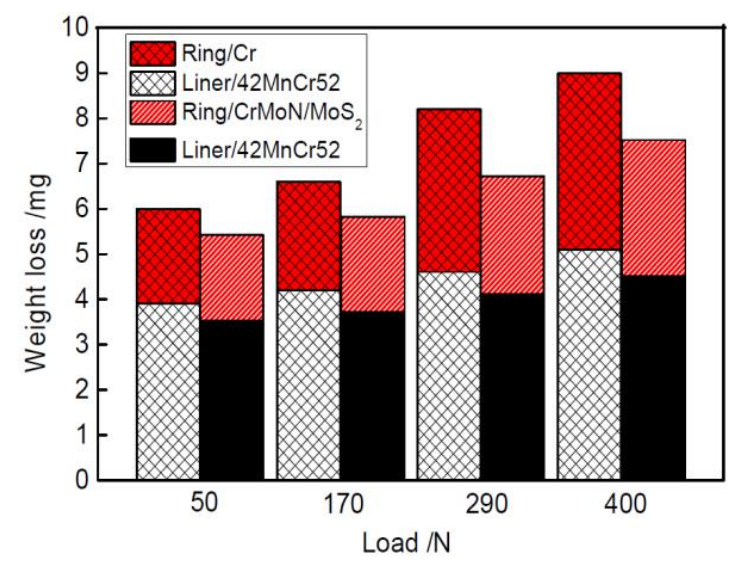

Figure 7. Wear weight loss of friction pairs under different load conditions.

From Figure 9, it is known that the wear condition of the $\mathrm{CrMoN} / \mathrm{MoS}_{2}$ friction pair is obviously better than $\mathrm{Cr}$ plating. There are only some slight furrows on the surface of the $\mathrm{CrMoN} / \mathrm{MoS}_{2}$ piston ring at the load of $50 \mathrm{~N}$, showing abrasive wear form (Figure 10a1,a2). The plough on the surface of the $\mathrm{CrMoN} / \mathrm{MoS}_{2}$ piston ring and cylinder liner deepens as the load increases. When the load is $400 \mathrm{~N}$, the wear mechanism is mainly abrasive wear, as well as some slight adhesive wear (Figure 10d1,d2). According to the transform film theory of self-lubricating composite coatings, a relative motion happened between two materials, and the adhesive wear caused by plastic deformation can exist under contact stress at high load, transferring from the piston surface to another surface easily, and thus forming a transfer film on the grinding surface after continuously reciprocating friction, adhesion and peeling.

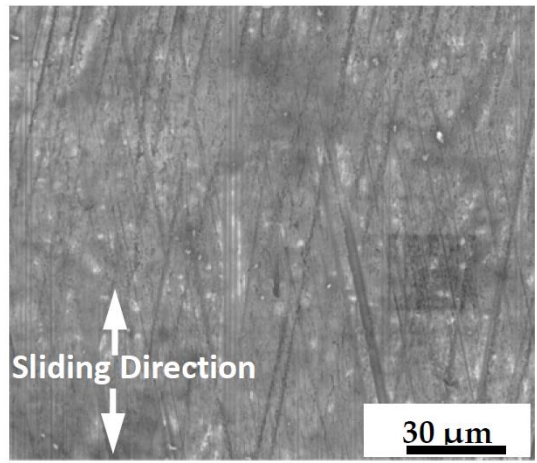

(a1)

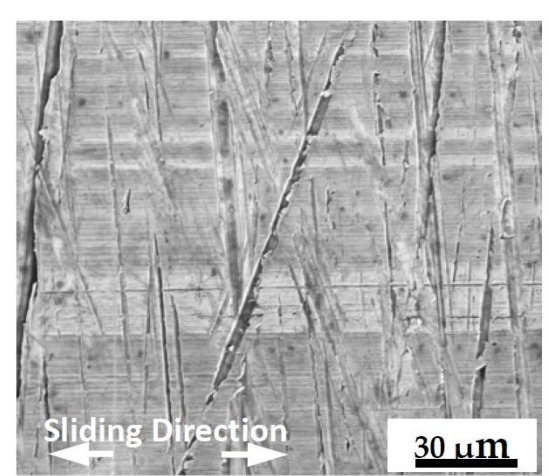

(a2)

Figure 8. Cont. 


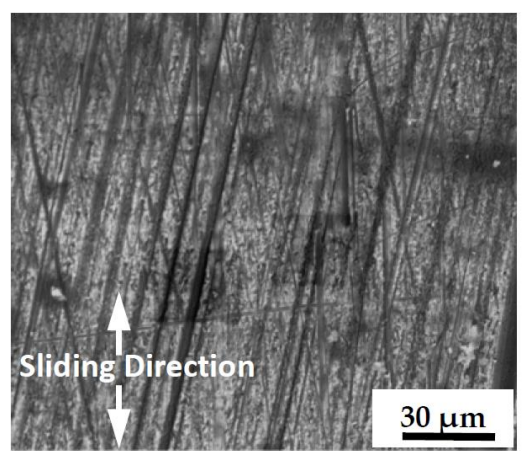

(b1)

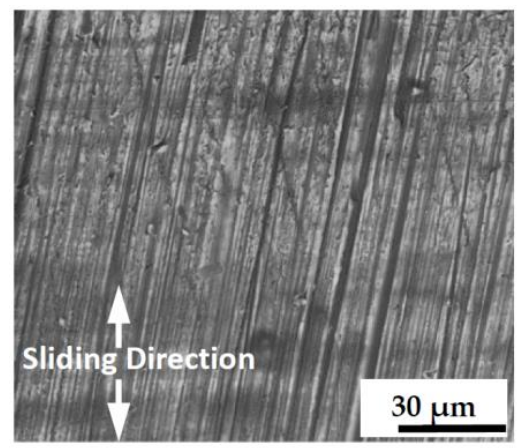

(c1)

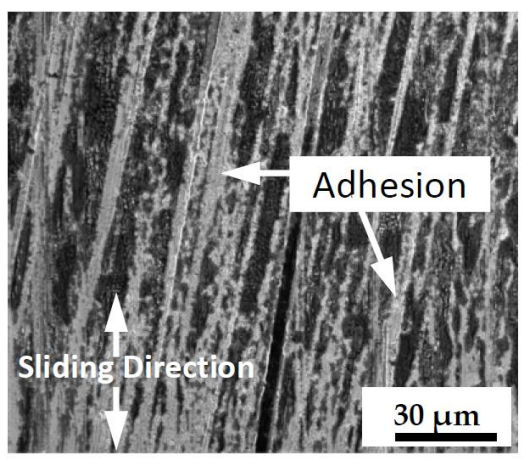

(d1)

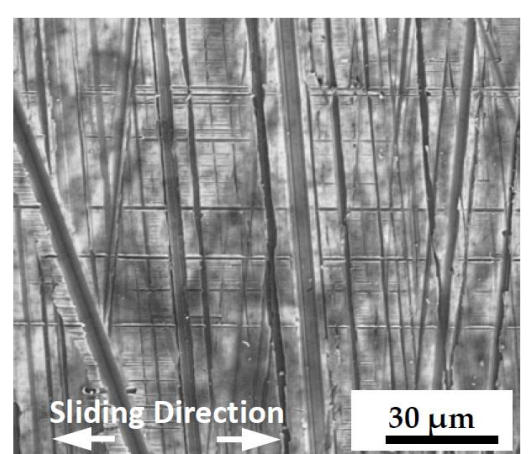

(b2)

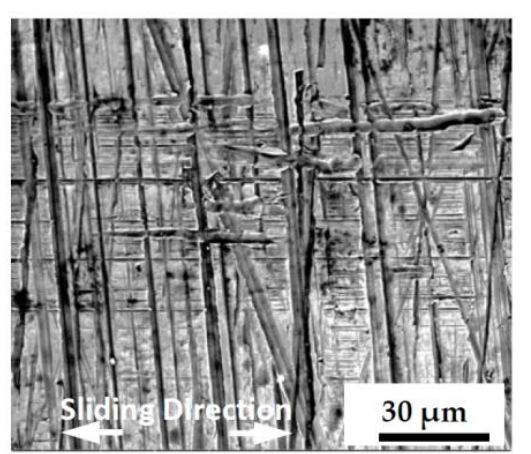

(c2)

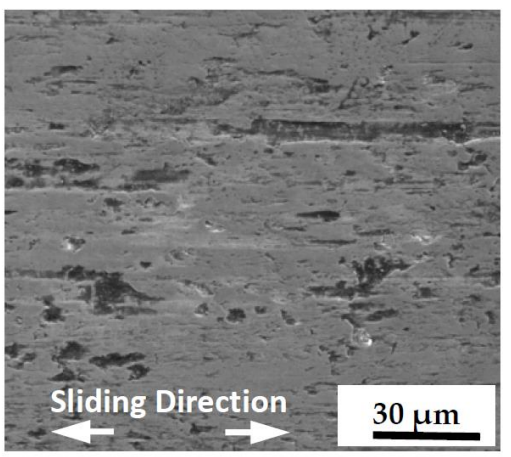

(d2)

Figure 8. The morphology of the wear scar of the $\mathrm{Cr}$ electroplated friction pair under different static loads. (a1) Piston ring, 50 N; (a2) Cylinder, 50 N; (b1) Piston ring, 170 N; (b2) Cylinder, 170 N; (c1) Piston ring, 290 N; (c2) Cylinder, 290 N; (d1) Piston ring, 400 N; (d2) Cylinder, 400 N.

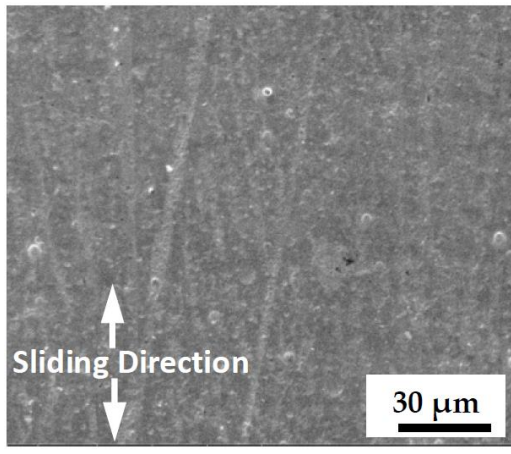

(a1)

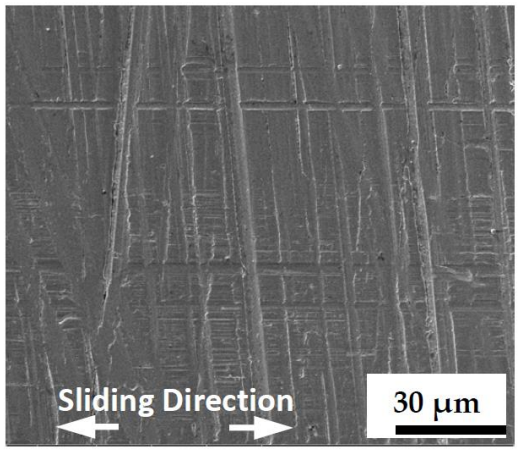

(a2)

Figure 9. Cont. 


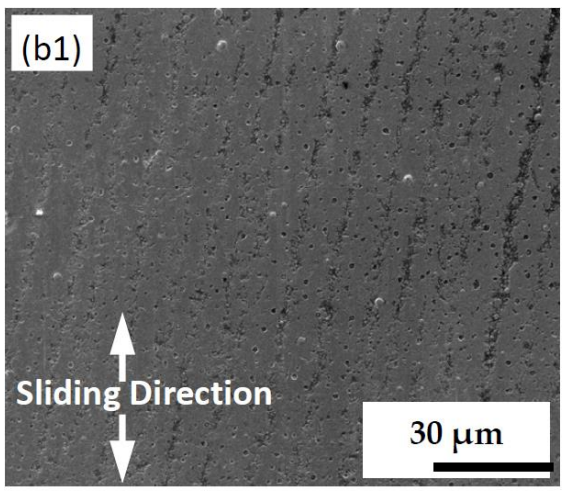

(b1)

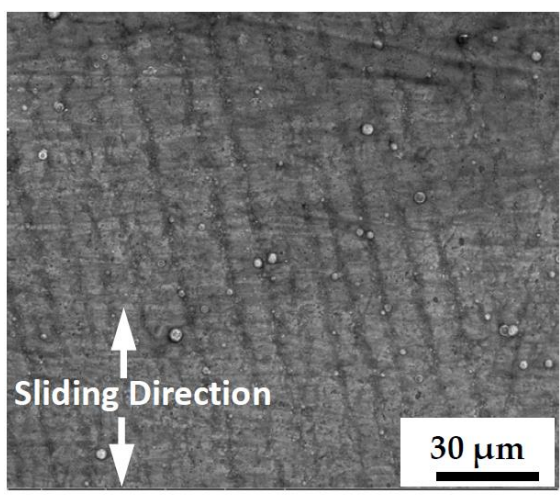

(c1)

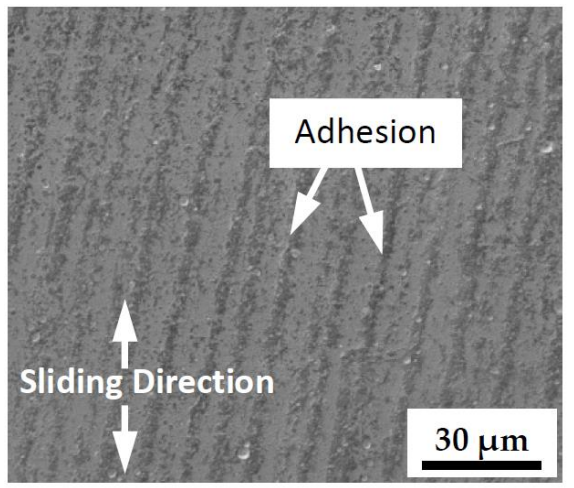

(d1)

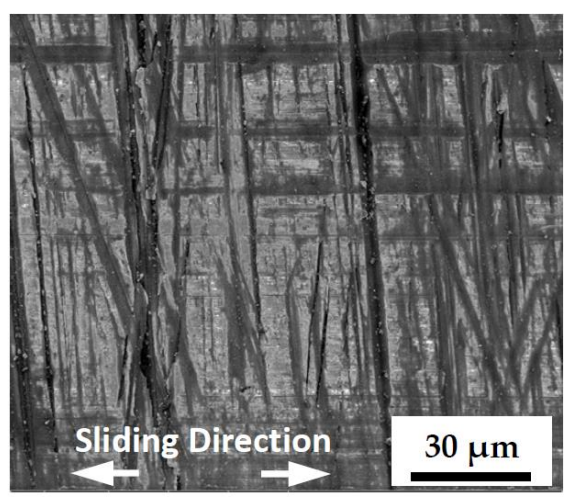

(b2)

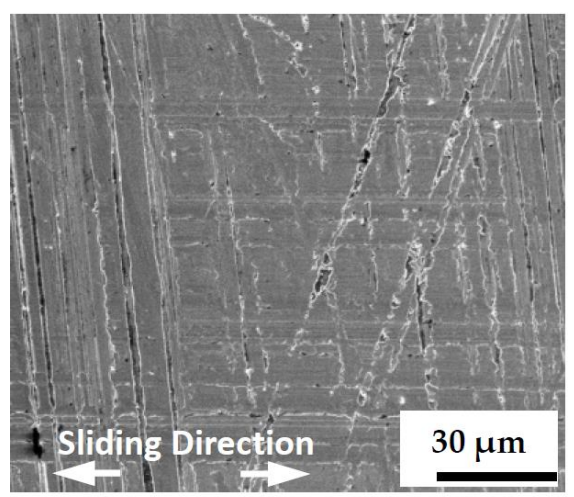

(c2)

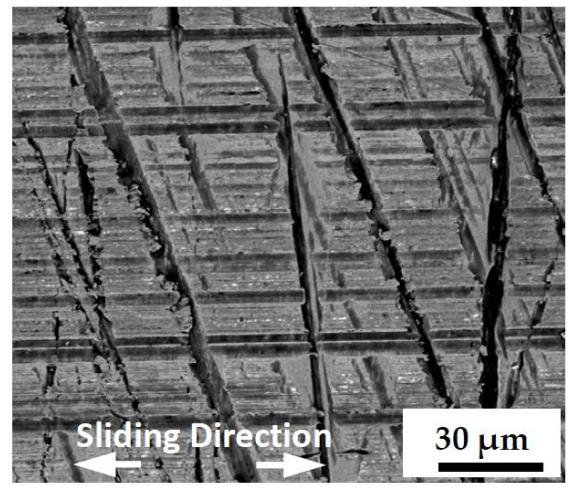

$(\mathrm{d} 2)$

Figure 9. The morphology of the wear scar of the electroplating $\mathrm{Cr}$ friction pairs under different static loads. (a1) Piston ring, 50 N; (a2) Cylinder, 50 N; (b1) Piston ring, 170 N; (b2) Cylinder, 170 N; (c1) Piston ring, 290 N; (c2) Cylinder, 290 N; (d1) Piston ring, 400 N; (d2) Cylinder, 400 N.

The Electron spectrometer (EDS) analysis result is shown in Figure 10. It can be seen that there are still S and Mo elements on the surface of the piston ring under the high load of $400 \mathrm{~N}$. In the friction process, the solid lubricant film can reduce the direct contact of the micro convex body of the friction pair, which is easily transferred under high plastic stress, and adheres to the grinding cylinder liner, thus reducing wear and tear. 

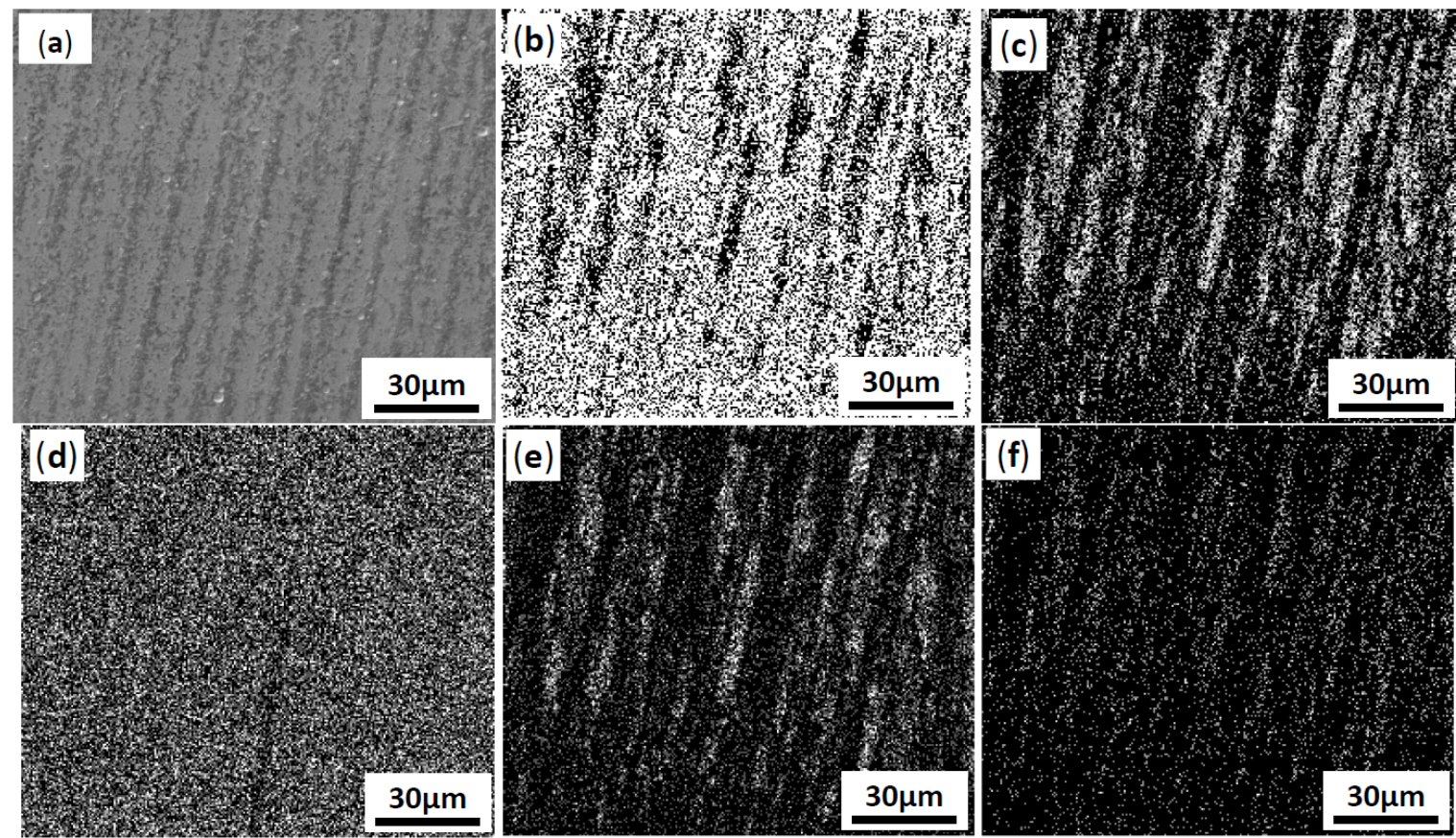

Figure 10. Element distribution of wear surface of the $\mathrm{CrMoN} / \mathrm{MoS}_{2}$ piston ring under a load of $400 \mathrm{~N}$.

(a) Wear surface; (b) Cr; (c) N; (d) O; (e) Mo; (f) S.

\section{Conclusions}

Close-field unbalanced magnetron sputtering and low temperature ion sulfurizing technology are combined to prepare $\mathrm{CrMoN} / \mathrm{MoS}_{2}$ composite coatings. Based on the results of this study, we arrive at the following conclusions:

(1) Compared with $\mathrm{Cr}$ plating, the $\mathrm{CrMoN} / \mathrm{MoS}_{2}$ coating shows a dense and compact surface structure, and its grains are fine and granular. A composite phase structure was formed on the surface of the $\mathrm{CrMoN} / \mathrm{MoS}_{2}$ composite coating after sulfurizing. The outer surface is $\mathrm{MoS}_{2}$ with antifriction and lubricant effects, and the subsurface is $\mathrm{CrN}$ and $\mathrm{Mo}_{2} \mathrm{~N}$ with high hardness.

(2) The average nano-hardness and Young's modulus of the $\mathrm{CrMoN} / \mathrm{MoS}_{2}$ composite coating was 29.2 and 347.1, respectively, which was much higher than those of Cr plating.

(3) Under poor lubrication friction conditions, as the static load and frequency increases, the friction coefficient of both kinds of coating decreased; the friction coefficient of the $\mathrm{CrMoN} / \mathrm{MoS}_{2}$ solid lubricating composite coating was lower than that of the $\mathrm{Cr}$ plating layer, and under high load conditions, the $\mathrm{Cr}$ electroplated friction pair wear amount is larger and the wear mechanism changed into complicated grinding abrasive wear and adhesive wear. The wear weight loss of the $\mathrm{CrMoN} / \mathrm{MoS}_{2}$ composite coating was far below that of the $\mathrm{Cr}$ electroplated friction pair, showing superior antifriction and wear resistance performance.

Acknowledgments: This work was financially supported by the National Natural Science Foundation under Grant (No. 50901089) and National Key laboratory for remanufacturing under Grant (Project No. 9140C850207100C8506).

Author Contributions: For research articles with several authors, a short paragraph specifying their individual contributions must be provided. Zhihai Cai and Yuelan Di conceived and designed the experiments; Yuelan Di performed the experiments; Yuelan Di analyzed the data; Ping Zhang contributed reagents/materials/analysis tools; Yuelan Di wrote the paper.

Conflicts of Interest: The authors declare no conflict of interest. 


\section{References}

1. Liu, H. A Comprehensive Study on Nano-Lubricant in Piston Set and Cylinder Liner of Internal Combustion Engine for Heat Transfer and Lubrication Friction; Dalian University of Technology: Dalian, China, 2015.

2. Nakasa, M. Engine friction overview. In Proceedings of the International Tribology Conference, Yokohama, Japan, 29 October-2 November 1995.

3. Spearot, J.A. Friction, wear, health, and environmental impacts-tribology in the new millennium. Presented at the STLE Annual Meeting, Nashville, Tennessee, 22-26 May 2000.

4. Li, Q.; Wang, X.C.; He, X.G.; Cai, Z.-H.; He, M. Wear Failure Mechanism of Cylinder Liner-Piston Ring Friction Pair for High Power Diesel Engines. China Surf. Eng. 2012, 25, 36-41. [CrossRef]

5. Zhang, Q.M.; Liu, W.J. Wear performance of cast iron piston rings strengthened by laser. Chin. J. Met. 2006, 16, 447-452.

6. Cai, Z.H.; Di, Y.L.; Zhang, P. Microstructure and tribological property of Cr/CrN nano-multilayer film deposited on piston ring. J. Shenyang Univ. Technol. 2011, 33, 375-381.

7. Hao, Q.G.; Wang, Y.; Jia, X.S.; Zuo, X.W.; Chen, N.L. Dynamic compression behavior and microstructure of a novel low-carbon quenching-partitioning-tempering steel. Acta Metall. Sin. 2014, 27, 444-451. [CrossRef]

8. Aouadi, S.M.; Gao, H.Y.; Martini, A.; Muratore, C. Lubricious oxide coatings for extreme temperature applications: A review. Surf. Coat. Tchanol. 2014, 257, 266-277. [CrossRef]

9. Zhang, N.; Zhuang, D.M.; Liu, J.J.; Fang, X.D.; Guan, M.X. Wear mechanisms of ion-sulphurization layer on steel under dry conditions. Wear 2001, 247, 1-8.

10. Wang, H.D.; Zhuang, D.M.; Wang, K.L.; Liu, J.-J. Comparative investigation on tribological properties of ion-sulfuration layers under dry friction. Tribol. Lett. 2002, 13, 55-61.

11. Jensen, M.F.; Bǿttiger, J.; Reitz, H.H.; Benzon, M.E. Simulation of wear characteristics of engine cylinders. Wear 2002, 253, 1044-1056. [CrossRef]

12. Renevier, N.M.; Fox, V.C.; Teer, D.G.; Hampshire, J. Coating characteristics and tribological properties of sputter-deposited $\mathrm{MoS}_{2}$ metal composite coatings deposited by closed field unbalanced magnetron sputter ion plating. Surf. Coat. Technol. 2000, 127, 24-37. [CrossRef]

13. Guo, C.; Chen, J.M.; Zhou, J.S.; Zhou, H.D. Microstructure and tribological properties of TiAg intermetallic compound coating. Appl. Surf. Sci. 2011, 257, 10692-10698. [CrossRef]

14. La, P.Q.; Ma, J.Q.; Zhu, Y.T.; Valiev, R.Z. Dry-sliding tribological properties of ultrafine-grained Ti prepared by severe plastic deformation. Acta Mater. 2005, 53, 5167-5173. [CrossRef] 